\title{
CT and MRI features of tumors and tumor-like lesions in the abdominal wall
}

\author{
Meng Li, Li Zhang, Xiao-Juan Xu, Zhuo Shi, Xin-Ming Zhao \\ Department of Diagnostic Radiology, National Cancer Center/National Clinical Research Center for Cancer/Cancer Hospital, Chinese Academy of \\ Medical Sciences and Peking Union Medical College, Beijing 100021, China
}

Correspondence to: Xin-Ming Zhao. Department of Diagnostic Radiology, National Cancer Center/National Clinical Research Center for Cancer/ Cancer Hospital, Chinese Academy of Medical Sciences and Peking Union Medical College, No. 17 Panjiayuan Nanli, Chaoyang District, Beijing 100021, China. Email: zhaoxinming@cicams.ac.cn.

\begin{abstract}
Masses involving the abdominal wall are common in clinical practice and have many etiologies, including tumors and tumor-like lesions. Abdominal wall tumors include primary and secondary tumors, the former of which constitute a heterogeneous group of soft tissue tumors with their own unique spectrum. Tumor-like lesions, such as hernias, are more common and must be distinguished from true tumors. Medical imaging is valuable for discovering, diagnosing, and evaluating the extent of abdominal wall masses. With the increasing application of computed tomography (CT) and magnetic resonance imaging (MRI), determining a diagnosis or narrowing the differential diagnosis is often possible, thus facilitating effective management. In this article, we comprehensively review the spectrum of common abdominal wall masses and present the CT and MRI features of typical cases in our hospital. A systematic stepwise diagnostic approach is also proposed for clinical practice.
\end{abstract}

Keywords: Abdominal wall; computed tomography (CT); magnetic resonance imaging (MRI); soft tissue tumor; tumor-like lesion

Submitted Jan 17, 2019. Accepted for publication Sep 02, 2019.

doi: 10.21037/qims.2019.09.03

View this article at: http://dx.doi.org/10.21037/qims.2019.09.03

\section{Background}

The abdomen is a very accessible part of the human body, and clinically accessible abdominal masses are particularly common. Some of these lesions arise from abdominal and pelvic organs, such as the liver, gallbladder, gastrointestinal tract, and ovaries, while others manifest in the abdominal wall itself. The abdominal wall anatomy is relatively superficial and hierarchical. The abdominal wall is divided into four major layers: the skin, superficial fascia, deep fascia and enveloped inner muscles, and the peritoneal fascia. A wide variety of masses are derived from the above structural layers, including both true tumors and tumor-like lesions. According to one cohort study, benign masses accounted for $57.8 \%$ and malignant masses accounted for $42.2 \%$ of these masses (1).

Because most abdominal wall lesions are superficial, ultrasound (US) is usually the preferred imaging modality by virtue of its convenience, economy, and high resolution, although the US is operator-dependent and can be problematic for deep and large lesions. The popularization of computed tomography (CT) and magnetic resonance imaging (MRI), have led to their playing an increasingly important role and having great diagnostic value in modern medicine. MRI is widely considered the optimal imaging technique in the evaluation of soft tissue tumors (2). MRI provides high-resolution images of soft tissues, which can be imaged in any orientation. Basic sequences, such as $\mathrm{T}_{1^{-}}$ weighted imaging $\left(\mathrm{T}_{1} \mathrm{WI}\right), \mathrm{T}_{2}$-weighted imaging $\left(\mathrm{T}_{2} \mathrm{WI}\right)$, and $\mathrm{T}_{2} \mathrm{WI}$ with fat suppression $\left(\mathrm{T}_{2} \mathrm{WI} / \mathrm{FS}\right)$, and even diffusion-weighted imaging (DWI) and contrast-enhanced imaging, are generally required. CT has less advantage in the diagnosis of abdominal wall masses, but it can be used 
Table 1 Common masses in the abdominal wall according to traditional classification

Benign tumors
Lipomas
Desmoid fibromatosis
Hemangiomas
Neurogenic tumors
Malignant tumors
Soft tissue sarcomas
Lymphomas
Metastases
Tumor-like lesions
Hernias
Endometriosis
Hematomas
Abscesses

in a wide range of examinations to reveal relationships with adjacent vital structures and simultaneously help find distant sites of metastasis.

Remarkably, most abdominal wall masses can be easily detected by palpation or US, and biopsy can be used to obtain tissue for histological analysis. However, CT and MRI have advantages during presurgical planning due to their ability to determine the mass size, location, and relationship with adjacent anatomical structures. For some lesions, CT and MRI can detect pathognomonic signs, such as pure fluid, fat, blood products, phleboliths, and feeding or draining vessels. These imaging features and information on clinical characteristics are extremely valuable for presurgical diagnosis and can be a beneficial complement to biopsy results, which may be indefinite due to the sample location and size, especially in soft tissue tumors.

This article comprehensively reviews the CT and MRI features of common causes of abdominal wall masses based on our experience and relevant literature, including cases confirmed in our hospital. According to the traditional abdominal wall mass classification $(1,3)$, lesions are often classified as benign tumors, malignant tumors, and tumorlike lesions (Table 1). However, in the new World Health Organization (WHO) classification of soft tissue tumors (4), some traditional benign or malignant tumors are classified as intermediate tumors (Table 2). Therefore, in this article, we review abdominal wall masses in a new classification of primary tumors, secondary tumors, and tumor-like lesions. Finally, we propose a systematic stepwise diagnostic approach for abdominal wall masses.

\section{Primary tumors in the abdominal wall}

Primary tumors in the abdominal wall are almost all soft tissue tumors, except for cancer and melanoma derived from skin, which is easily identified by clinicians. Soft tissue tumors can occur at almost any site and represent a biologically diverse group of benign and malignant tumors. Abdominal wall soft tissue tumors account for approximately $10 \%$ of all soft tissue tumors (5). Compared with soft tissue lesions in other areas of the body, abdominal wall masses have both general and unique characteristics. Tables 2 and 3 show the most common soft tissue tumors in the abdominal wall according to the WHO classification and demonstrates the relatively unique spectrum and characteristics of these diseases, which we will introduce below.

\section{Adipocytic tumors}

Lipomatous tumors are mesenchymal tumors composed of fat with varying differentiation and rate of components. Common lipomatous tumors include benign lipomas, intermediate atypical lipomatous tumors (ALTs)/welldifferentiated liposarcomas (WDLs), and malignant liposarcomas. The differentiation of these tumors can range from mature adipose tissue histologically indistinguishable from normal subcutaneous fat to little or no microscopic adipocytic differentiation.

\section{Lipomas}

Lipomas are the most common soft tissue tumors, accounting for approximately $50 \%$ of all soft tissue tumors, and are the most common subcutaneous neoplasms (6-9). Lipomas occur most commonly in adults and are more common in obese patients (8). Lipomas are also regarded as the most common tumors affecting the abdominal wall (10). Abdominal wall lipomas are usually painless and present as mobile superficial masses.

Classically, lipomas are soft tissue masses with a homogeneous mature adipose tissue density or signal on CT or MRI (Figure 1). Thin fibrous septa less than $2 \mathrm{~mm}$ in thickness are sometimes seen $(8,9,11)$. The thin septa can be enhanced after contrast administration, which is more advantageous with MRI than with CT (12). Occasionally, 
Table 2 Common primary tumors in the abdominal wall according to WHO classification

\begin{tabular}{|c|c|c|}
\hline Classification & Character/behavior & Tumor \\
\hline \multirow{2}{*}{ Adipocytic tumors } & Intermediate (locally aggressive) & $\begin{array}{l}\text { Atypical lipomatous tumors/well-differentiated } \\
\text { liposarcomas }\end{array}$ \\
\hline & Malignant & Liposarcomas \\
\hline Vascular tumors & Benign & Hemangiomas \\
\hline \multirow[t]{2}{*}{ Nerve sheath tumors } & Benign & Schwannomas \\
\hline & & Neurofibromas \\
\hline
\end{tabular}

Table 3 Key points of common tumor and tumor-like lesions in the abdominal wall

\begin{tabular}{|c|c|c|}
\hline Classification & Masses & Key points \\
\hline \multirow{6}{*}{ Primary tumors } & Liposarcomas & Complex fat signal \\
\hline & Desmoid-type fibromatosis & $\begin{array}{l}\text { Female of childbearing age; fascial tail sign; slow growing; } T_{2} \text { low } \\
\text { signal region }\end{array}$ \\
\hline & Dermatofibrosarcoma protuberans & Confined within the skin \\
\hline & Benign peripheral nerve sheath tumors & Nerve-related; fusiform shape; target signs; split fat sign; myxoid areas \\
\hline & Malignant peripheral nerve sheath tumors & Associated with type 1 neurofibromatosis; heterogeneous signal \\
\hline & Undifferentiated pleomorphic sarcomas & Infiltrating large masses; heterogeneous signal \\
\hline \multirow[t]{4}{*}{ Tumor-like lesions } & Hernias & Contain content from the abdominal cavity \\
\hline & Endometriosis & $\begin{array}{l}\text { Female of childbearing age; history of uterine surgery; cyclical pain; } \\
\text { blood products }\end{array}$ \\
\hline & Hematomas & Trauma; anticoagulants; blood products \\
\hline & Abscesses & Contain fluid; high DWI signal; rim enhancement \\
\hline
\end{tabular}

superficial, simple lipomas may be difficult to distinguish from adjacent adipose tissue.

\section{ALTs/WDLs}

Apart from location, ALTs and WDLs are synonymous with each other and exhibit intermediate behavior. ALTs are usually subcutaneous lesions in the extremities, where they can be readily resected. Additionally, these tumors are not as threatening as WDLs occurring in deeper locations. ALTs/WDLs represent the most common liposarcomas, 

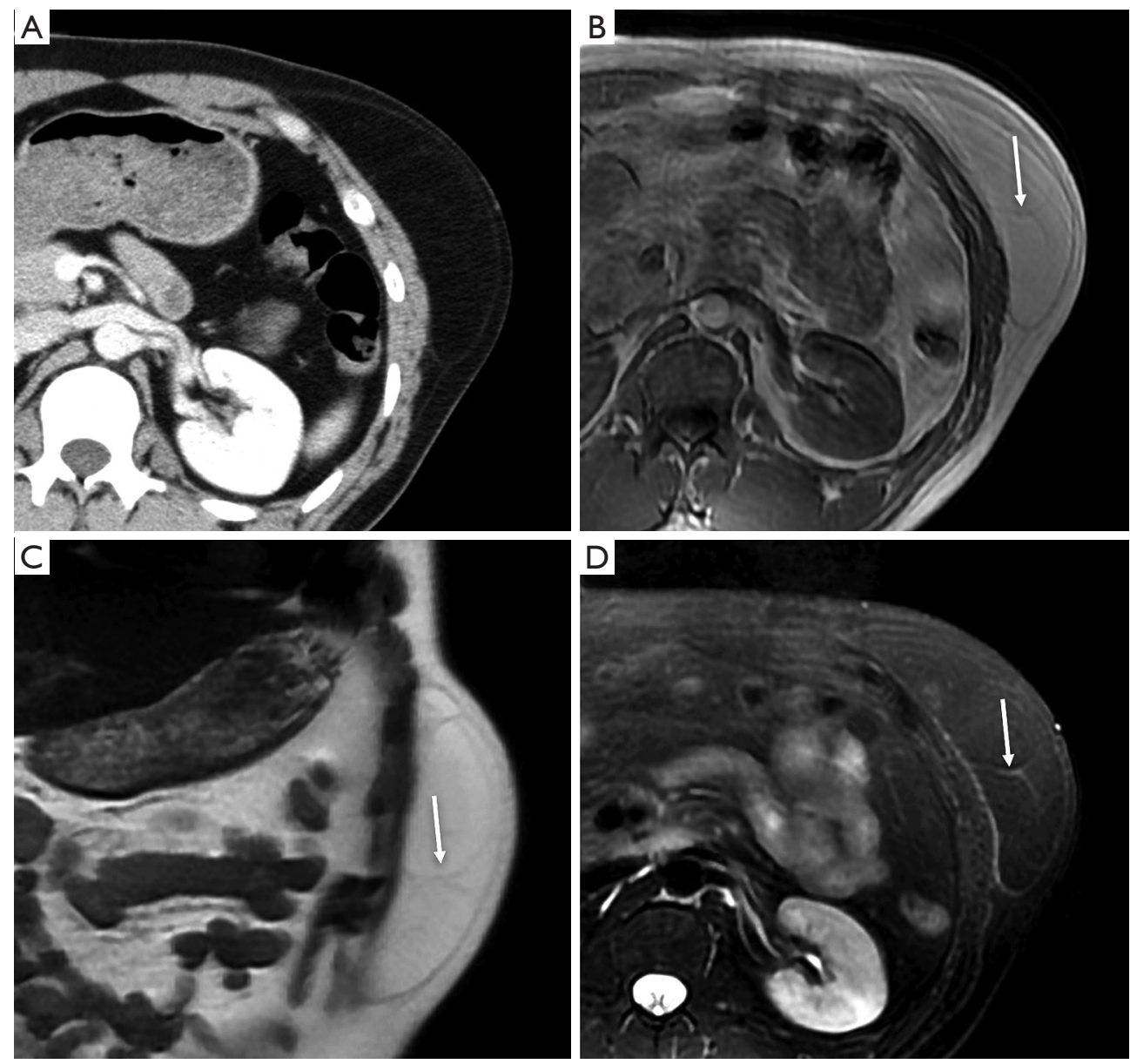

Figure 1 A left anterior abdominal wall subcutaneous lipoma in a 29-year-old male. (A) Axial contrast-enhanced CT is displaying a dense fat mass in the subcutaneous tissue of the left abdominal wall with a thin capsule and fibrous septa; $(\mathrm{B}, \mathrm{C})$ axial $\mathrm{T}_{1} \mathrm{WI}$ and coronal $\mathrm{T}_{2} \mathrm{WI}$ displaying a mass with the same $\mathrm{T}_{1}$ and $\mathrm{T}_{2}$ signals as fat, with a low-signal, thin capsule, and septa (arrow); (D) axial $\mathrm{T}_{2} \mathrm{WI}$ with fat suppression displaying a markedly decreased signal from the lesion, with a high-signal, thin capsule, and septa (arrow). $\mathrm{T}_{1} \mathrm{WI}, \mathrm{T}_{1}$-weighted imaging; $T_{2} W I, T_{2}$-weighted imaging.

accounting for approximately $50 \%$ of all liposarcomas (13).

On CT and MRI, ALTs/WDLs typically have a relatively characteristic appearance of predominantly adipose masses containing nonlipomatous components (14-20). Distinguishing ALTs/WDLs from benign lipoma can be challenging and often requires histological evaluation. Imaging features suggesting an ALT/WDL or liposarcoma include tumor heterogeneity, thickened or irregular nodular septa (generally more than 2-mm thick), nodular soft tissue or nonadipose components, and incomplete fat suppression with linear or nodular hyperintense areas on MRI (9,12,19-22) (Figure 2).

\section{Liposarcomas}

Liposarcomas are the second most common soft tissue sarcomas, accounting for $10-35 \%$ of all soft tissue sarcomas (13). Liposarcomas show the most striking diversity in pathological and biological behavior and can be categorized into several subtypes, including dedifferentiated, myxoid, pleomorphic, and mixed (23). The imaging findings of liposarcomas are frequently distinct. On CT and MRI, focal or diffuse areas of fat associated with nonlipomatous components are commonly detected, and the diagnosis can be easily determined in these cases. However, the diagnosis is not achievable in other cases without fatty tissue in the 

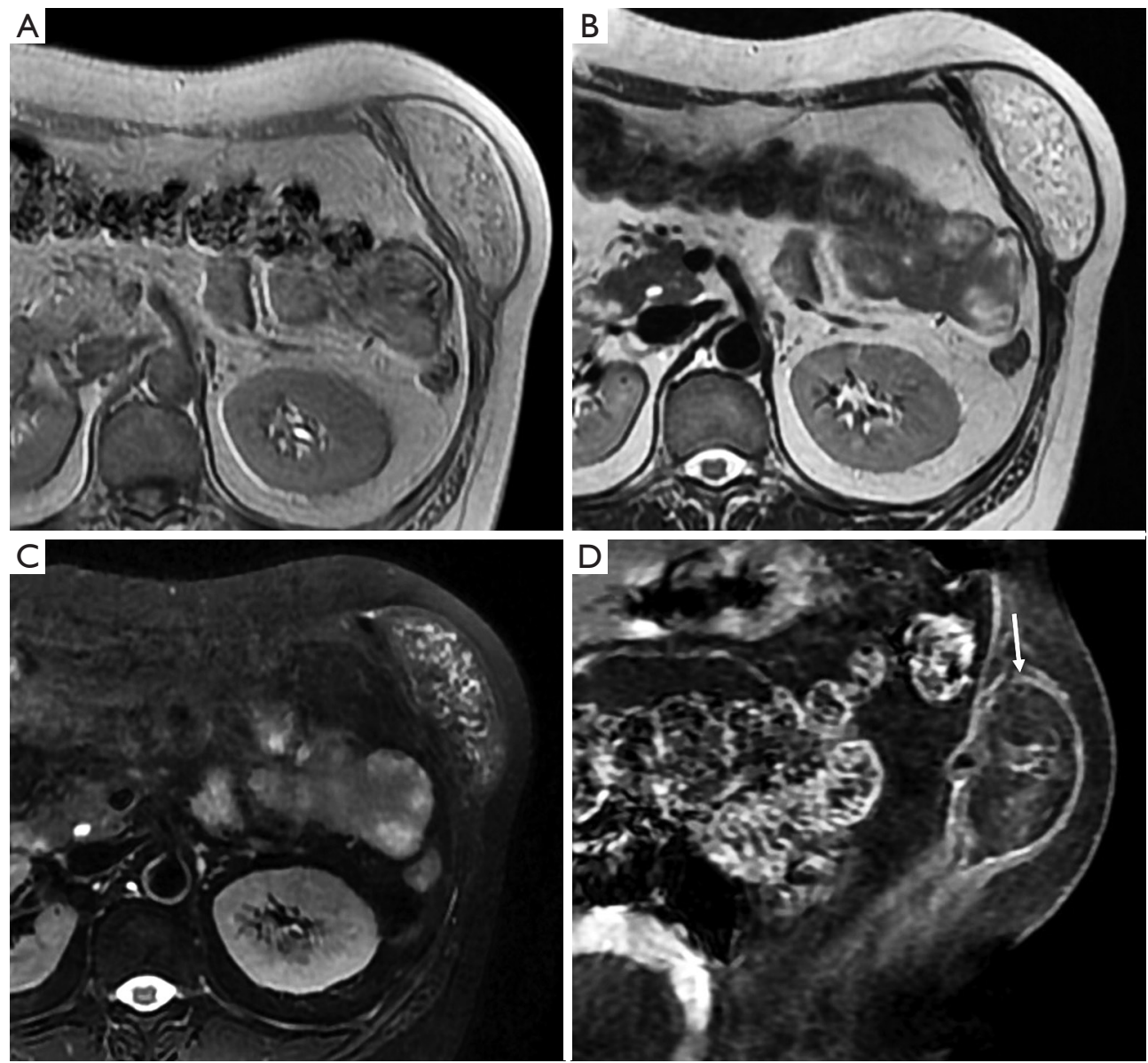

Figure 2 A well-differentiated liposarcoma in the left anterior abdominal wall of a 48-year-old female. (A,B,C) Axial $T_{1} W I, T_{2} W I$ and $\mathrm{T}_{2} \mathrm{WI}$ with fat suppression showing a heterogeneous, predominantly adipose mass containing nonlipomatous components with a low signal on $\mathrm{T}_{1} \mathrm{WI}$ and a high signal on $\mathrm{T}_{2} \mathrm{WI}$; (D) Coronal $\mathrm{T}_{1} \mathrm{WI}$ image after contrast agent injection showing a thick capsule and enhancement of the nonlipomatous components (arrow). $T_{1} W I, T_{1}$-weighted imaging; $T_{2} W I, T_{2}$-weighted imaging.

lesions (Figure 3). MRI is useful for distinguishing welldifferentiated from poorly differentiated liposarcomas (11).

\section{Fibroblastic/myofibroblastic tumors}

Fibroblastic/myofibroblastic tumors constitute a large heterogeneous group of neoplastic lesions in clinical practice and occur in patients of all ages. This paper describes the two most common tumors occurring in the abdominal wall.

\section{Desmoid-type fibromatosis}

Desmoid-type fibromatosis is a relatively rare fibroblastic proliferative disease, previously referred to as aggressive fibromatosis or desmoid tumors. These tumors do not metastasize, but relapse can easily occur after surgical treatment. In some studies, desmoid-type fibromatosis has been described as the most common soft tissue tumor in the abdominal wall $(1,24)$; however, this may be because lipomas are not usually treated surgically and were excluded from the analysis. Typically, these tumors occur in young females aged 20 to 40 years, more frequently during the first year after childbirth (25). Arising from the aponeurosis of the abdominal wall muscle, desmoid fibromatosis usually occurs in the anterior abdominal wall and is usually located in the rectus abdominis, the internal oblique muscles, and the surrounding fascia. Due to the distinct location and tendency of these lesions to develop in women of childbearing age, they can usually be distinguished from other forms of deep desmoid-type fibromatosis. 

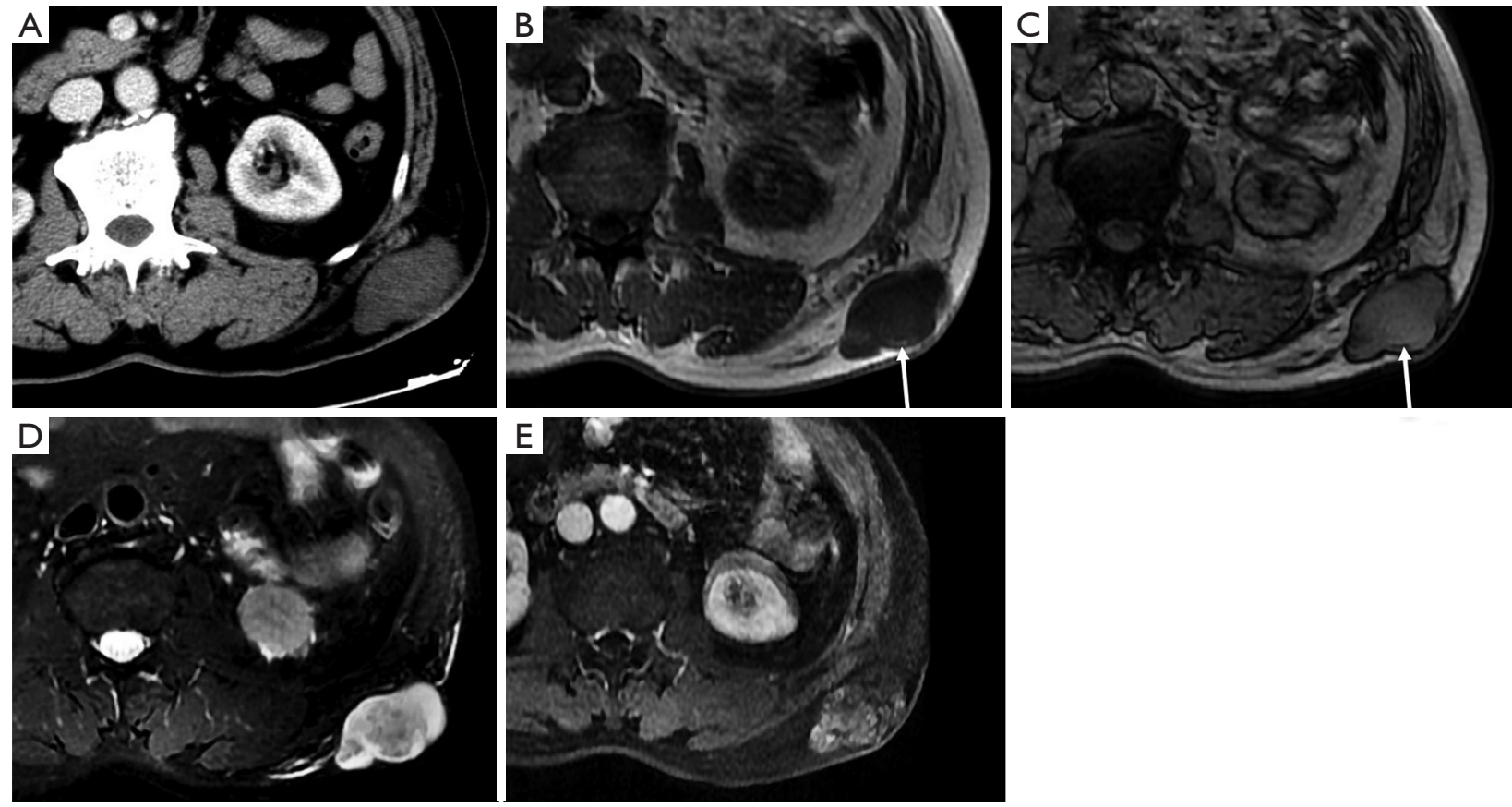

Figure 3 A myxoid liposarcoma in the left posterior abdominal wall of a 66-year-old female. (A) Axial contrast-enhanced CT displaying a soft tissue mass. (B,C,D) Axial CT, in-phase $T_{1} W I$, out-phase $T_{1} W I$, and $T_{2} W I$ with fat suppression displaying a nonlipomatous mass with a low signal on $T_{1} W I$ and a high signal on $T_{2} W I$ with fat suppression. The small area shows a high signal on in-phase $T_{1} W I$, and the low signal on out-phase $T_{1} W I$ may represent a small area of fat (arrow). (E) Axial $T_{1} W I$ after contrast agent injection showing heterogeneous enhancement. $T_{1} W I, T_{1}$-weighted imaging; $T_{2} W I, T_{2}$-weighted imaging.

On CT, desmoid-type fibromatosis usually appears as a round or oval, nonspecific soft tissue mass with a density similar to that of muscle. Generally, it does not grow across the midline and is significantly enhanced after contrast injection. It shows low-to-intermediate signal intensity (SI) on $T_{1} W I$ and high SI on $T_{2} W I$. Internal band-like findings of low signal heterogeneity on all sequences are relatively distinct on MRI (Figure 4). These low-SI bands are common (62-91\% of cases) in desmoid-type fibromatosis compared with other neoplastic lesions and are related to the collagenized and hypocellular band regions observed on gross pathological examination, representing fibrous and collagenized regions $(26,27)$. Extension along fascial planes (i.e., the "fascial tail" sign) adds specificity for the diagnosis (Figure 3) $(24,28)$. MRI is optimal for detecting deep intraabdominal extension that, although unusual, is important for guiding complete surgical resection. High SI on $\mathrm{T}_{2} \mathrm{WI}$ has been shown to correlate with greater cellularity and an increased recurrence rate (29).

\section{Dermatofibrosarcoma protuberans (DFSP)}

DFSP is a relatively uncommon sarcoma that arises from the dermis but is considered the most common mesenchymal cutaneous malignancy. The trunk is the most common site of DFSP involvement, and DFSP accounts for approximately $20 \%$ of all abdominal wall sarcomas (1). DFSP is a low-grade, locally aggressive tumor with low metastatic potential. Local recurrence has been observed in $20-55 \%$ of cases and metastases have been observed in less than $5 \%$ of cases (30). DFSP is more common in adults between 20 and 50 years, with no sex bias.

On imaging, DFSP typically presents as a wellcircumscribed, multinodular, noncalcified solid mass arising from the skin and extending into subcutaneous tissue with moderate enhancement (30-33) (Figure 5). On CT, the attenuation is similar to that of muscle. On MRI, DFSP often appears isointense compared to muscle on $\mathrm{T}_{1} \mathrm{WI}$ scans, homogeneous with high SI on $\mathrm{T}_{2} \mathrm{WI}$ scans, and avid enhanced on contrast-enhanced images. Although the 

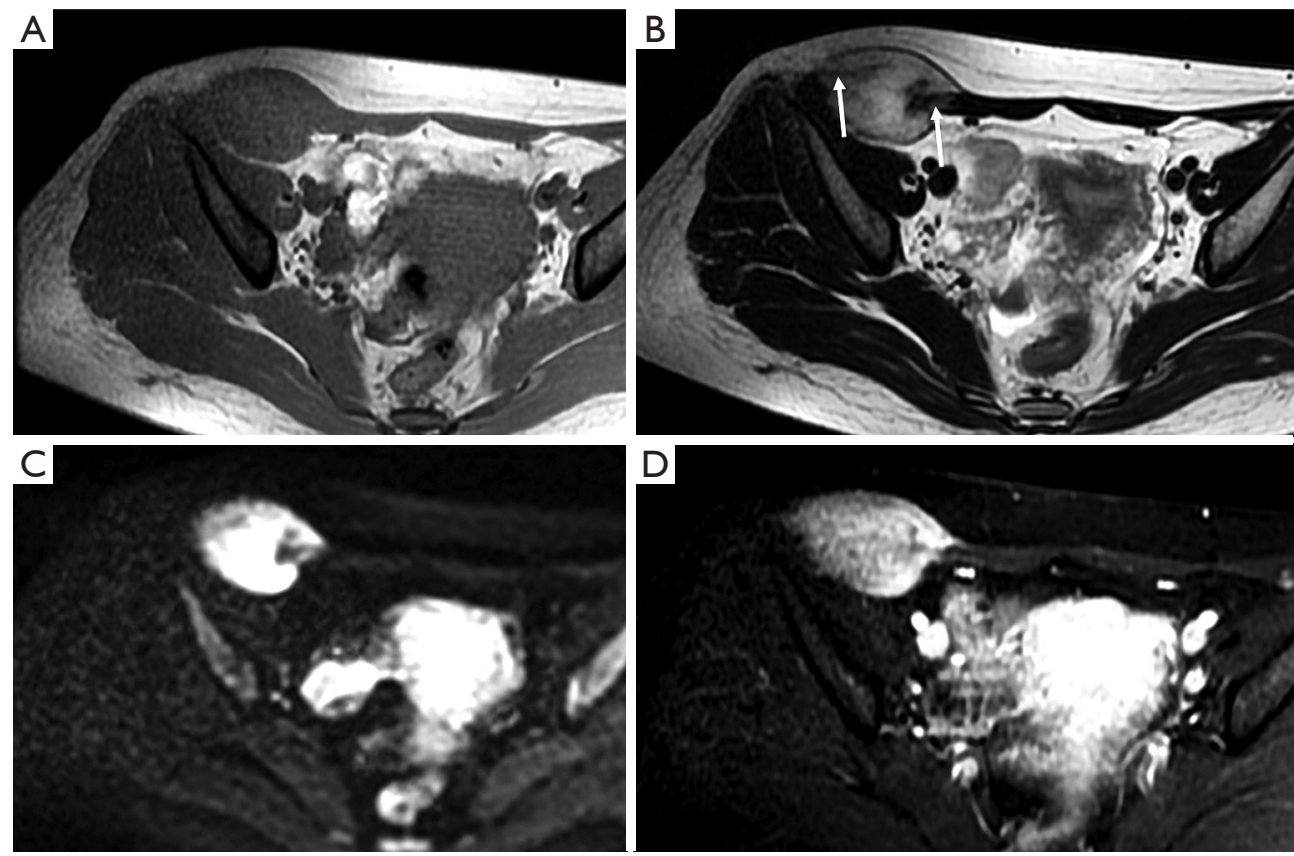

Figure 4 A desmoid-type fibromatosis in a 28-year-old female. (A) Axial $T_{1} W I,(B) T_{2} W I$, and (C) DWI revealing a lesion in the right oblique abdominal wall, with isointensity on $T_{1} W I$ and hyperintensity on $T_{2} W I$ along with mixed internal heterogeneity. (D) Contrastenhanced MRI revealing intense enhancement. Areas with low $\mathrm{T}_{2}$ signals (arrow) correspond to fibrosis, whereas areas with high $\mathrm{T}_{2}$ signals correspond to increased cellularity. The combination of low-signal bands within the lesion and at the lesion margins extending into the surrounding fascia (the "fascial tail" sign) is considered to indicate desmoid-type fibromatosis. $\mathrm{T}_{1} W I, \mathrm{~T}_{1}$-weighted imaging; $\mathrm{T}_{2} \mathrm{WI}, \mathrm{T}_{2}$ weighted imaging; DWI, diffusion-weighted imaging.

intrinsic SI or attenuation is nonspecific, linear extension along the skin surface is suggestive of the diagnosis (34). More importantly, imaging can help delineate the extent of the lesion and detect satellite nodules for accurate preoperative assessment.

\section{Vascular tumors}

Vascular tumors are very common soft tissue masses, particularly in young patients in the first three decades of life, and are frequently confused with other neoplastic masses both clinically and radiologically $(34,35)$. The most common superficial vascular tumors are hemangiomas, which are benign lesions.

\section{Hemangiomas}

Hemangiomas are heterogeneous and can be histologically classified as capillary, cavernous, arteriovenous, or venous by the predominant type of vascular channels identified within the lesion. Therefore, the radiological appearance of hemangiomas also varies, causing them to be frequently confused with other neoplastic masses when the imaging results are atypical.

CT often shows a poorly defined nodule or mass with attenuation similar to that of skeletal muscle in nonenhanced imaging, and marked enhancement of the serpentine vascular components may be observed after intravenous administration of contrast medium. Moreover, CT is the most sensitive modality for identifying calcifications and phleboliths in the lesions, which are characteristic of hemangiomas (36). MRI often shows lowto-intermediate SI on $\mathrm{T}_{1} \mathrm{WI}$ scans and very high SI on $\mathrm{T}_{2}$ WI scans (37). Hemangiomas typically show prominent progressive enhancement after intravenous administration of gadolinium (Figure 6).

\section{Nerve sheath tumors}

Nerve sheath tumors are also very common soft tissue tumors that arise from the nerves. Most nerve sheath 

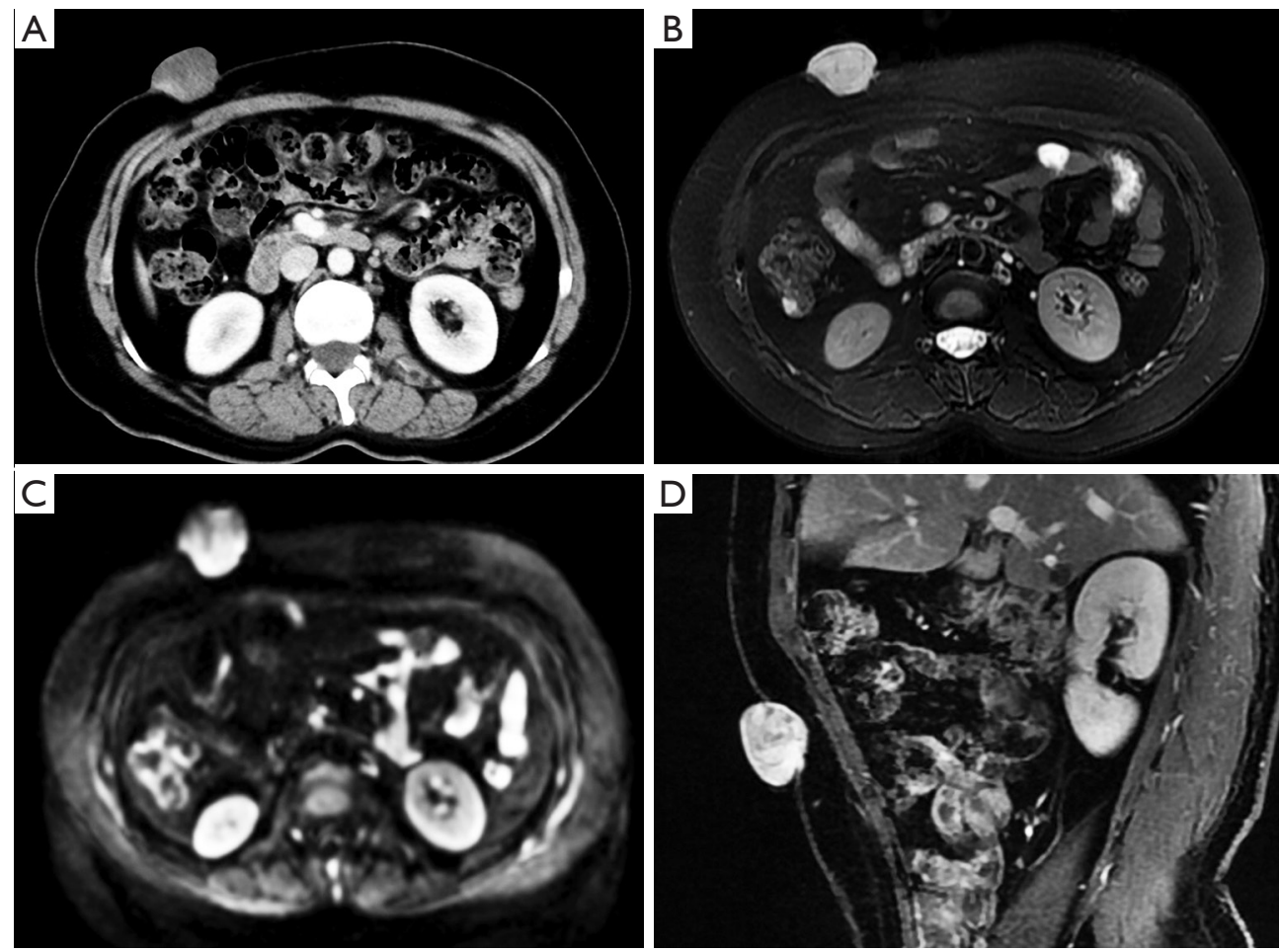

Figure 5 A dermatofibrosarcoma protuberans in the right anterior abdominal wall of a 57-year-old male. (A) Axial contrast-enhanced CT displaying a soft tissue protuberant nodule at the skin surface and extending into subcutaneous tissue. (B) Axial $\mathrm{T}_{2}$ WI with fat suppression and (C) DWI showing a uniform, high-signal nodule. (D) Sagittal $\mathrm{T}_{1} \mathrm{WI}$ after intravenous administration of gadolinium showing marked enhancement. $T_{1} W I, T_{1}$-weighted imaging; $T_{2} W I, T_{2}$-weighted imaging; DWI, diffusion-weighted imaging.

tumors are benign.

\section{Benign peripheral nerve sheath tumors (PNSTs)}

Benign PNSTs can appear as well-defined, smoothbordered, fusiform masses that are aligned along a nerve. On CT, they typically show lower attenuation than muscle and strong enhancement. They are typically isointense compared with muscle on $\mathrm{T}_{1} \mathrm{WI}$ and slightly hyperintense compared to fat on $T_{2} W I$. The "split fat sign" is associated with benign PNSTs; as a tumor grows, a surrounding rim of normal fat is maintained (38) (Figure 7). In some cases, a "target sign" appearance may be observed on $\mathrm{T}_{2} \mathrm{WI}$; the central low $\mathrm{T}_{2}$ SI histologically corresponds to fibrocollagenous tissue, whereas the outer high $\mathrm{T}_{2}$ SI corresponds to myxomatous tissue (39) (Figure 7).

Schwannomas and neurofibromas are the two main types of benign PNSTs, and they are difficult to distinguish on imaging $(39,40)$. The histological hallmark of schwannomas is the presence of Antoni A and Antoni B regions. Antoni A areas are hypercellular and composed of spindle cells, while Antoni B regions are hypocellular, contain more myxoid tissue, and have a high water content $(41,42)$. Large schwannomas commonly undergo degenerative changes, including cyst formation, calcification, hemorrhage, and fibrosis (43). Therefore, myxoid areas with high $\mathrm{T}_{2}$ SI and degenerative regions are more common in schwannomas than in neurofibromas. However, "target signs" are more common in neurofibromas than in schwannomas (44). Occasionally, a schwannoma can be distinguished from a neurofibroma by its location relative to a nerve; schwannomas may be eccentrically adjacent to and separable from the nerve, whereas a neurofibroma may be integrated with the nerve (45).

\section{Malignant PNSTs}

Malignant PNSTs are uncommon soft tissue sarcomas accounting for up to $5 \%$ of all soft tissue sarcomas, and they are associated with type 1 neurofibromatosis in most cases (46-48). Malignant PNSTs can also be difficult to differentiate from benign PNSTs. Imaging features 

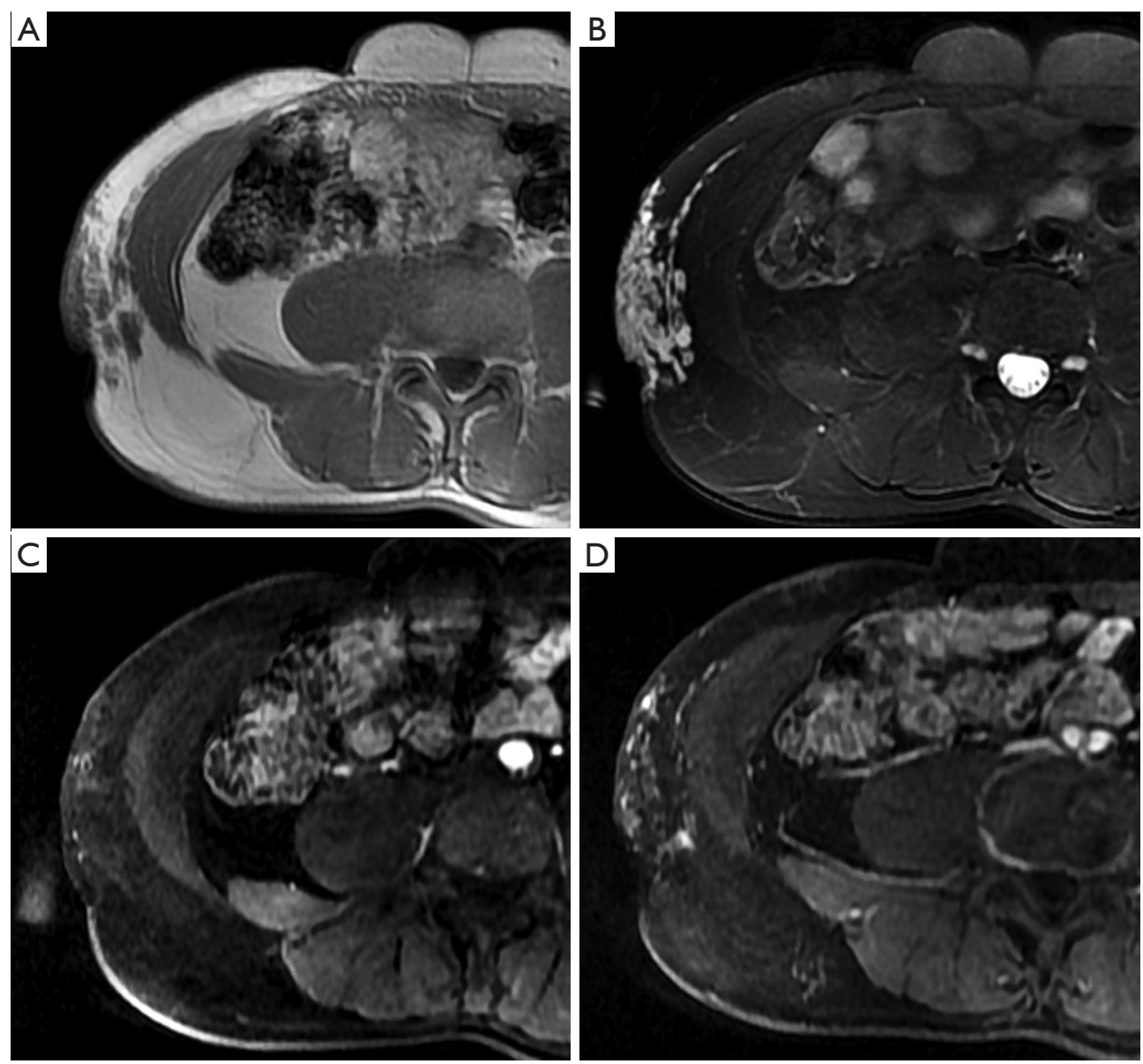

Figure 6 A hemangioma in the right abdominal wall of a 57-year-old male. (A) Axial $T_{1} W I$ and (B) $T_{2} W I$ with fat suppression showing subcutaneous diffuse lesions with heterogeneous low $T_{1}$ and high $T_{2}$ signals. (C,D) Axial contrast-enhanced $T_{1} W I$ in different phases showing heterogeneous enhancement with progressive enhancement over time. $T_{1} W I, T_{1}$-weighted imaging; $T_{2} W I, T_{2}$-weighted imaging.

suggestive of malignancy include rapid growth, large size $(>5 \mathrm{~cm})$, infiltrative margins, prominent vascularity or enhancement, marked heterogeneity with central necrosis, and hemorrhage (Figure 8). There are no specific imaging features that distinguish malignant PNSTs from other highgrade sarcomas, except possible origin from a large nerve.

\section{Undifferentiated/unclassified sarcomas}

Sarcomas of the abdomen account for approximately $5 \%$ of all sarcomas (1). Only soft tissue sarcomas show no definite histological differentiation and are classified as undifferentiated/unclassified sarcomas. Most of these lesions are undifferentiated pleomorphic sarcomas (UPSs), previously called malignant fibrous histiocytomas.

\section{UPSs}

UPSs are the most common soft tissue sarcomas occurring late in adult life and account for approximately $20 \%$ of all soft tissue sarcomas. UPSs are the most common sarcomas that develop at sites of prior irradiation (49).

Nonspecifically, UPSs appear as well-circumscribed, multinodular, or infiltrating large soft tissue masses that invade adjacent anatomical structures. On CT, UPSs demonstrate attenuation similar to that of muscle, with areas of decreased attenuation frequently apparent centrally within the mass corresponding to myxoid regions or necrosis (50). MRI often shows heterogeneous SI on all pulse sequences depending on the amounts of collagen, myxoid tissue, necrosis, and hemorrhage (Figure 9). Solid components of UPSs typically show enhancement after 

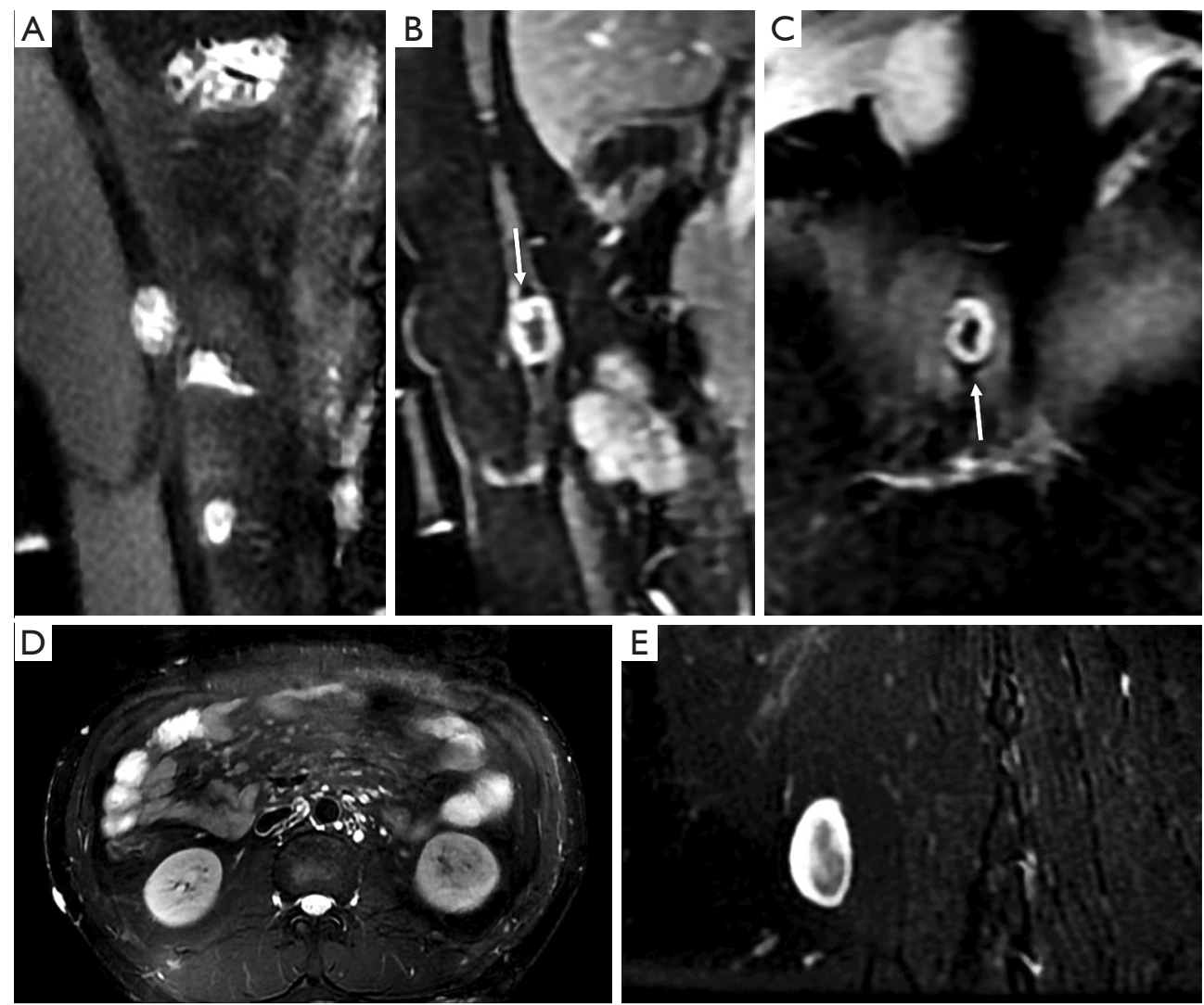

Figure 7 Benign peripheral nerve sheath tumors. (A,B,C) A schwannoma in the right abdominal wall of a 57-year-old male. (A) Sagittal $\mathrm{T}_{2} \mathrm{WI}$ with fat suppression showing a heterogeneous, hyperintense nodule in the intramuscular space. (B) Sagittal and (C) coronal $\mathrm{T}_{1} \mathrm{WI}$ after intravenous administration of gadolinium showing obvious peripheral enhancement. The central high $T_{2}$ signal and the nonenhanced component may represent myxoid areas. A surrounding rim of normal fat is maintained (arrow) (the "split fat sign"). (D,E) Neurofibromas in a 26-year-old male. (D) Axial and (E) coronal $\mathrm{T}_{2} \mathrm{WI}$ with fat suppression showing multiple extensive hyperintense subcutaneous nodules in the abdominal wall. The "target sign" can be clearly observed in a larger nodule, with a central area of low $\mathrm{T}_{2}$ signals and an outer area of high $\mathrm{T}_{2}$ signals. $\mathrm{T}_{1} \mathrm{WI}, \mathrm{T}_{1}$-weighted imaging; $\mathrm{T}_{2} \mathrm{WI}, \mathrm{T}_{2}$-weighted imaging.

intravenous administration of a contrast agent (51).

\section{Secondary tumors in the abdominal wall}

Secondary tumors in the abdominal wall refer to malignant tumors that reach the abdominal wall by direct invasion, metastasis, or implantation from other sites. In a cohort study, $41.6 \%$ of malignant masses were secondary cancers, and $3.2 \%$ were malignant hematolymphoid tumors, such as lymphomas (1).

\section{Metastases}

Metastases are the most common malignant lesions encountered in the anterior abdominal wall. The imaging characteristics of abdominal wall metastases are nonspecific, but they often resemble the known primary disease in other sites. The single most consistent discriminating feature is the rapid growth of lesions in a known cancer patient, who is usually at an advanced stage and has multiple other metastases. Metastasis of the umbilicus is known as Sister Mary Joseph's nodule and typically originates from cancers of the gastrointestinal tract and ovary (52-54). The proposed metastasis route of Sister Mary Joseph's nodule is along with the remnant structures at the umbilicus $(55,56)$. Metastasis to the surgical wound or laparoscopic trocar site and needle-tract seeding after radiofrequency ablation also lead to the formation of abdominal wall metastases (Figure 10). These specific metastases may not be associated with widespread disease in contrast to hematogenous abdominal 

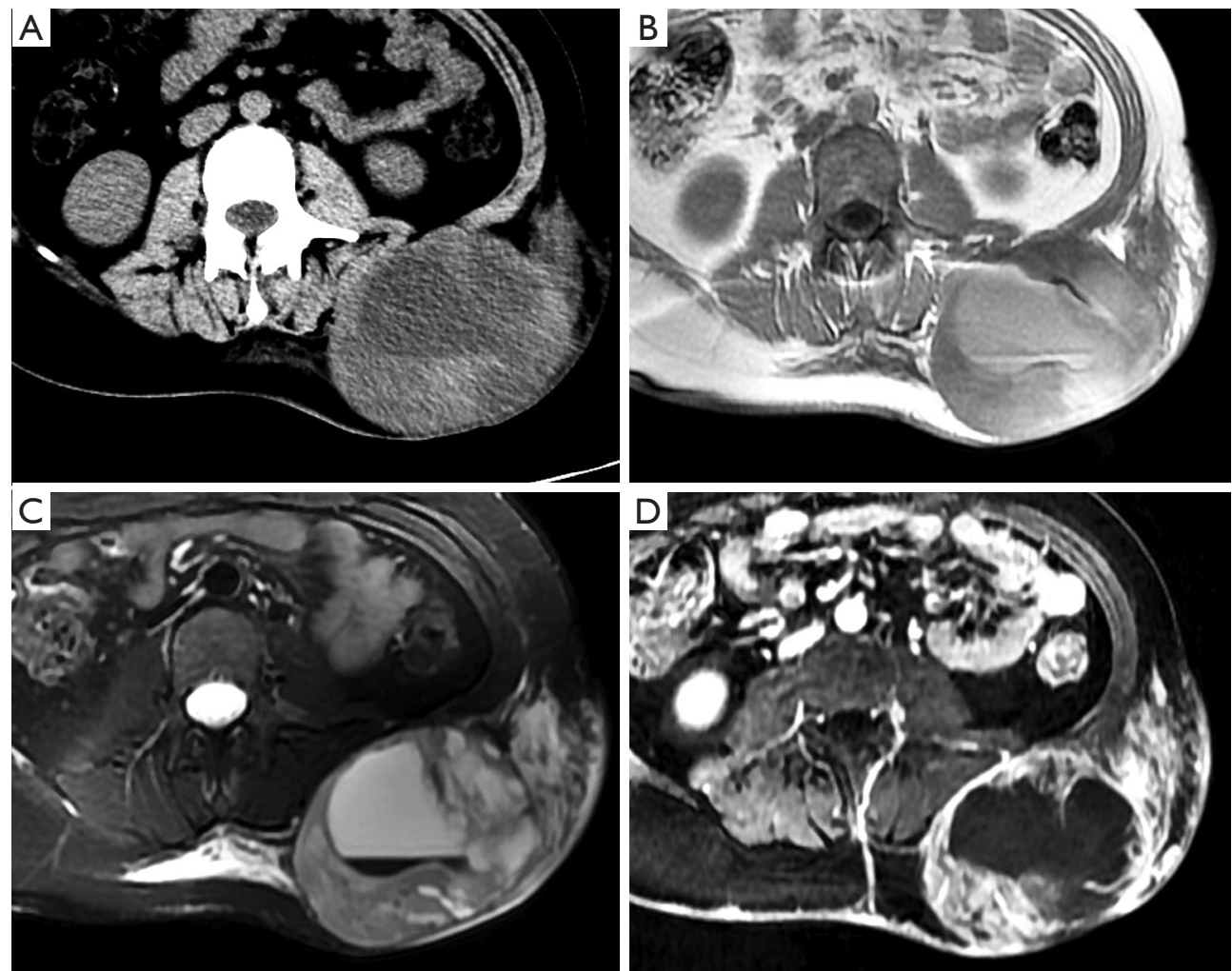

Figure 8 A malignant peripheral nerve sheath tumor in a 19-year-old female with a history of neurofibroma. (A) Axial CT showing a large $\left(>5 \mathrm{~cm}\right.$ ) mass with heterogeneous attenuation in the left posterior abdominal wall. (B,C,D) Axial $\mathrm{T}_{1} W I$, $\mathrm{T}_{2} W I$ with fat suppression, and contrast-enhanced $\mathrm{T}_{1} \mathrm{WI}$ showing heterogeneous signal and enhancement, a central necrosis/hemorrhage signal, and the fluid level. $\mathrm{T}_{1} \mathrm{WI}$, $\mathrm{T}_{1}$-weighted imaging; $\mathrm{T}_{2} \mathrm{WI}, \mathrm{T}_{2}$-weighted imaging.

wall metastases.

\section{Lymphomas}

Lymphomas may involve the skin, subcutaneous tissues, and muscles of the abdominal wall by contiguous extension or as isolated nodules. Lymphomas on CT or MRI often appear as multiple nodules with relatively homogeneous density or SI. The lesions also show homogeneous and moderate enhancement after administration of a contrast agent. On DWI, lymphomas have a hyperintense signal; i.e., the lesions have a lower apparent diffusion coefficient (ADC), which represents restricted free diffusion of water molecules (Figure 11). This restriction is likely because lymphomas have high cellularity and large abnormal nuclei and are therefore observed as more densely packed tissue (57). The diagnosis is primarily based on diffuse or systemic involvement.

\section{Tumor-like lesions in the abdominal wall}

"Tumor-like lesions" in the musculoskeletal system can be defined as lesions mistaken as tumors due to the presence of palpation upon physical examination or a tumor-mimicking appearance upon radiological examination (58). As the common tumor-like lesions in the abdominal wall, hernias, endometriosis, hematomas, and abscesses usually have a characteristic appearance both clinically and on crosssectional imaging, particularly on MRI, thus facilitating diagnosis. In some difficult or atypical cases, biopsy or follow-up is recommended.

\section{Hernias}

Hernias are actually the most common "masses" in the abdominal wall, and unlike tumors or other tumor-like lesions, they may develop acute complications requiring 

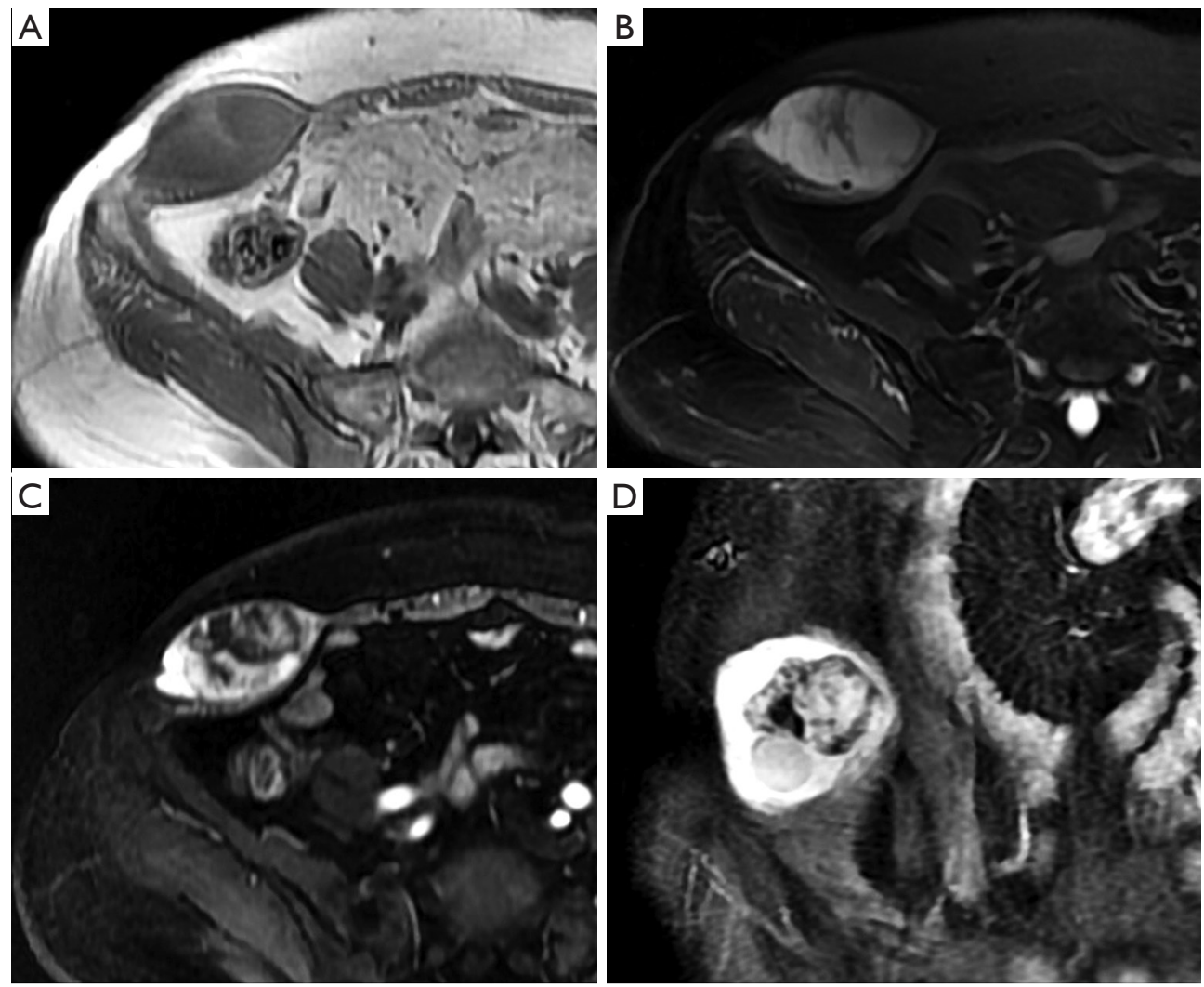

Figure 9 An undifferentiated pleomorphic sarcoma in a 61-year-old male. (A) Axial $T_{1} W I$ and (B) $T_{2} W I$ with fat suppression displaying a mass of fusiform shape in the right front abdominal wall with a heterogeneous low $T_{1}$ signal and high $T_{2}$ signal. (C) Axial $T_{1} W I$ and (D) coronal $\mathrm{T}_{1} \mathrm{WI}$ after intravenous administration of gadolinium showing heterogeneous enhancement in the mass. $\mathrm{T}_{1} \mathrm{WI}$, $\mathrm{T}_{1}$-weighted imaging; $T_{2} W I, T_{2}$-weighted imaging.

emergent surgery. Common abdominal wall hernias include upper abdominal wall hernias, lateral abdominal wall hernias (also known as meniscuses), umbilical hernias, and inguinal hernias, with the latter being the most common. Inguinal hernias can be oblique or direct hernias. In oblique hernias, the hernial sac enters the scrotum from the inguinal canal outside the inferior abdominal artery. In direct hernias, the hernial sac protrudes from the "inguinal triangle" or "Hesselbach triangle" on the medial side of the inferior abdominal artery.

Although the clinical diagnosis of abdominal hernias is relatively easy, CT or MRI can help distinguish between abdominal hernias and abdominal or abdominal wall tumors by showing the herniation of fat or intestines through the fascial defect, in addition to complications of intestinal fistulas, such as ischemia and obstruction (59).
As an interesting finding in our routine work, CT can be used to identify the inferior epigastric artery and can help distinguish oblique and direct hernias, which is important for surgery (Figure 12).

\section{Endometriosis}

The anterior abdominal wall is the most common site of extrapelvic endometriosis, which usually develops in a cesarean section scar, with a wide range of reported incidence rates of $0.03-3.5 \%$ (60). The most plausible cause of scar endometriosis is implantation of endometrial stem cells at the surgical site at the time of uterine surgery. Anterior wall endometriosis in patients with no prior surgeries is rare (61). Abdominal wall endometriomas are often the only manifestation of endometriosis with no 

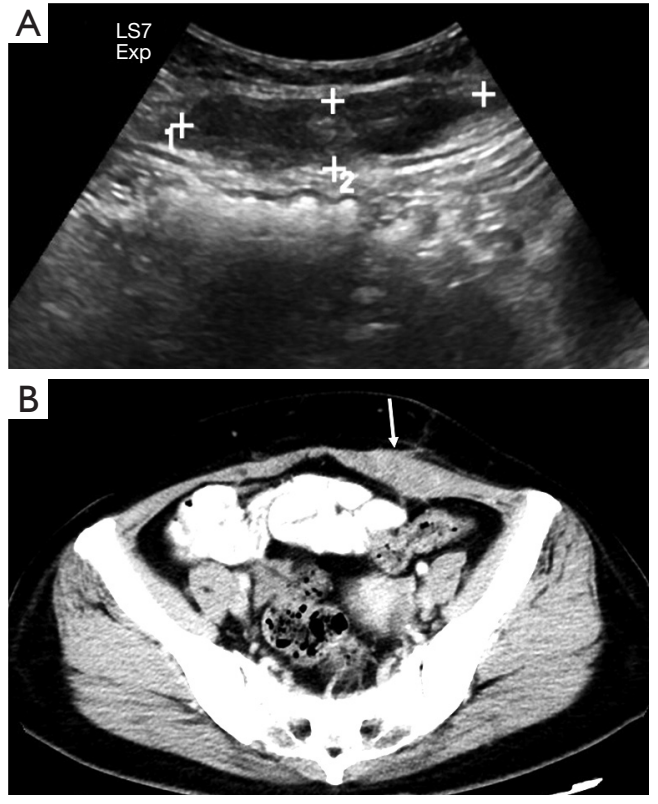

Figure 10 A laparoscopic trocar site metastasis confirmed by resection in a 46-year-old man with a colon cancer history. (A) Ultrasound and (B) axial contrast-enhanced CT of the pelvis revealing a heterogeneously enhanced metastatic deposit (arrow) in the left anterior abdominal pelvic wall at the site of trocar insertion during the previous laparoscopic colon cancer surgery. associated pelvic endometriosis. The typical presentation is a female patient with cyclical pain from a mass in scar tissue (62).

The appearance of abdominal wall endometriosis on CT and MRI depends on the phase of the patient's menstrual cycle, the chronicity of the process, the number of stromal and glandular elements, and the amounts of bleeding and associated inflammation (63). On CT, anterior abdominal wall endometriosis typically appears as a solid soft tissue mass that is hyperattenuated compared with muscle, although the attenuation can vary and be nonspecific. On MRI, it typically presents as a solid mass that is mildly hyperintense on both $T_{1} W I$ and $T_{2} W I$ as a result of subacute hemorrhage within the endometriotic crypts, although this finding may also vary (Figure 13). Mild to moderate contrast enhancement is present (60).

\section{Hematomas}

Anterior abdominal wall hematomas usually occur in the rectus abdominis muscle and result from damage, such as a trauma or surgical intervention, to the superior or inferior epigastric arteries or direct tearing of the rectus muscle. Other uncommon reasons are clotting deficiency
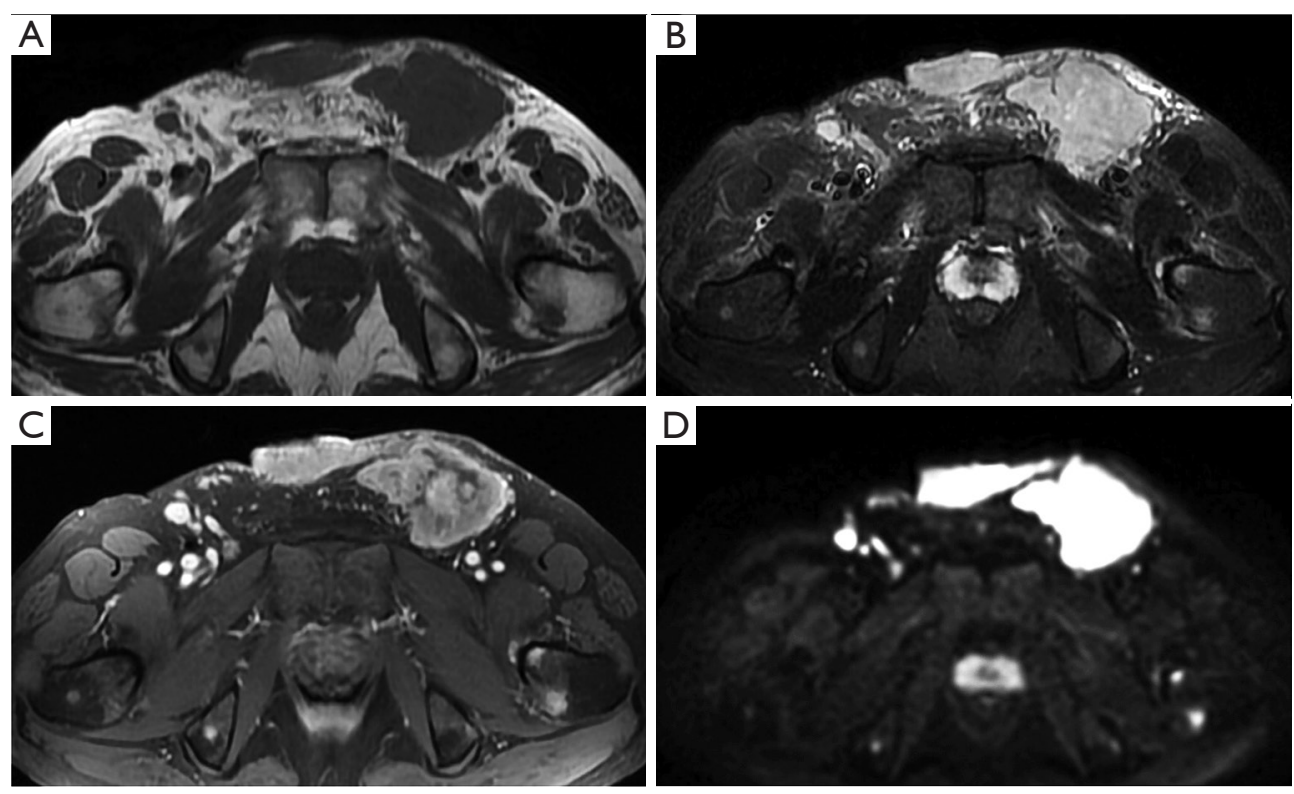

Figure 11 A diffuse lymphoma of the anterior abdominal wall of a 56-year-old man. (A) Axial $T_{1} W I$ and (B) $T_{2} W I$ with fat suppression revealing multiple subcutaneous nodules and masses with relatively homogeneous low $\mathrm{T}_{1}$ and high $\mathrm{T}_{2}$ signals characteristic of lymphoma. (C) Contrast-enhanced $\mathrm{T}_{1} \mathrm{WI}$ showing moderate enhancement. (D) DWI showing a hyperintense signal, indicating that the lesion has a lower ADC. $T_{1} W I, T_{1}$-weighted imaging; $T_{2} W I, T_{2}$-weighted imaging; DWI, diffusion-weighted imaging; ADC, apparent diffusion coefficient. 

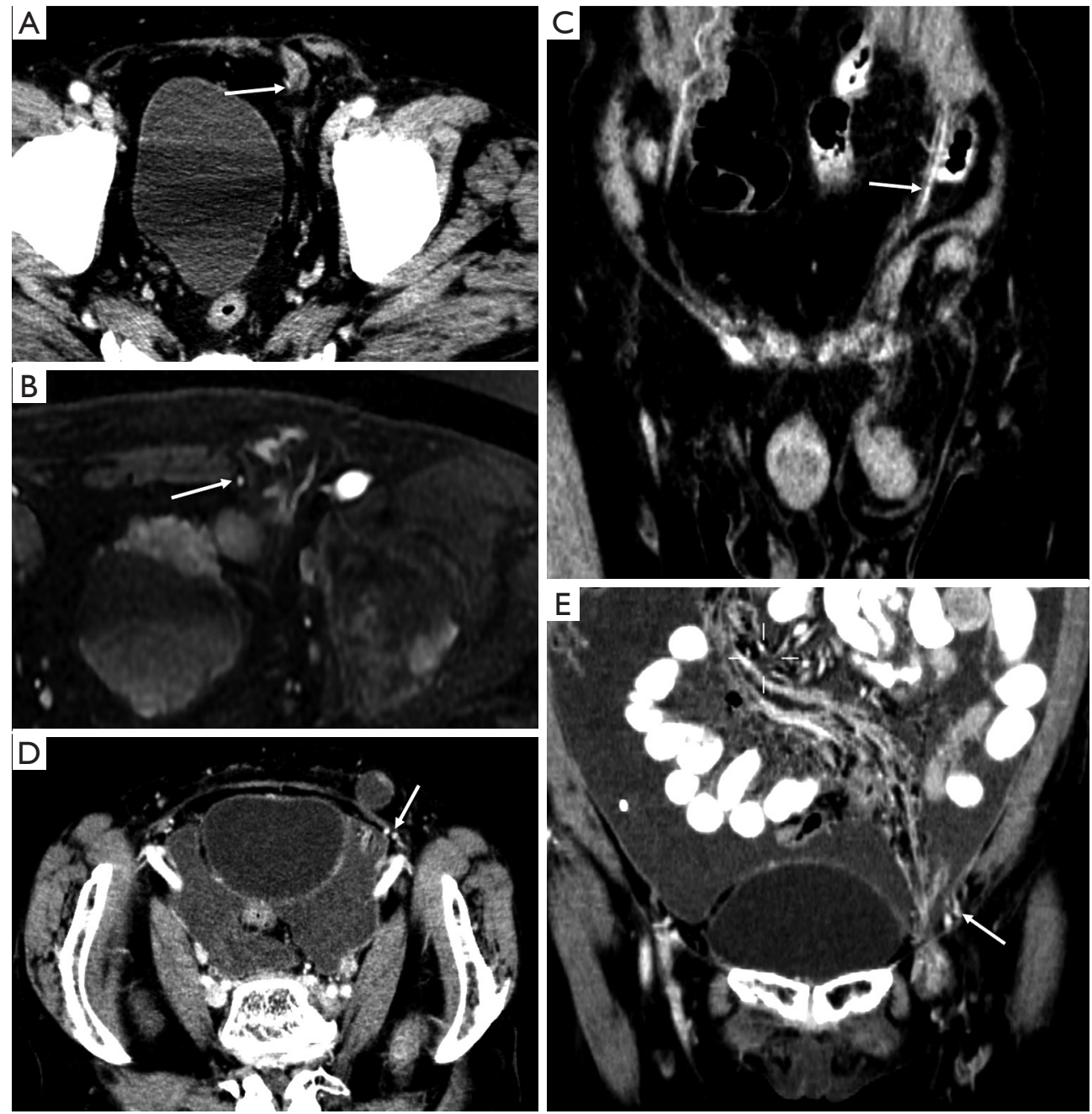

Figure 12 Inguinal hernias. (A,B,C) An indirect hernia in the left lateral abdominal wall of a 68-year-old man. (A) Axial contrast-enhanced CT, (B) contrast-enhanced $T_{1}$ WI, and (C) coronal contrast-enhanced CT showing the inguinal oblique hernia. The hernial sac was on the lateral side of the inferior epigastric artery (arrow) and herniated into the left scrotum. (D,E) A direct hernia in the left lateral abdominal wall of a 65-year-old woman. (D) Oblique axial contrast-enhanced CT and (E) coronal contrast-enhanced CT showing the direct inguinal hernia. The hernial sac was on the medial side of the inferior epigastric artery (arrow). $\mathrm{T}_{1} \mathrm{WI}, \mathrm{T}_{1}$-weighted imaging.

or anticoagulant treatment. Hematomas in the absence of trauma or after light trauma are usually difficult to distinguish from tumors with hemorrhage in clinical practice, and contrast-enhanced MRI will facilitate the differential diagnosis (64).

Hematomas present as well-defined, hyperdense rectus masses on unenhanced CT and may show active contrast extravasation on enhanced CT. Their appearance on MRI depends on the stage of the hemorrhage. Deoxyhemoglobin in the acute stage manifests as iso- or hypointense areas on $\mathrm{T}_{1} \mathrm{WI}$ and $\mathrm{T}_{2} \mathrm{WI}$. Methemoglobin in the subacute stage often produces high SI in the form of a peripheral rim, which is a very useful diagnostic factor (Figure 14). In the chronic phase, the dark hemosiderin rim on $\mathrm{T}_{1} \mathrm{WI}$ and $T_{2} W I$ is a useful discriminating feature (1). CT and MRI help achieve an accurate diagnosis and can be used to evaluate the extent of a hematoma and the presence of active bleeding (3).

\section{Abscesses}

Abscess, a focal collection of pus confined to a specific space, 

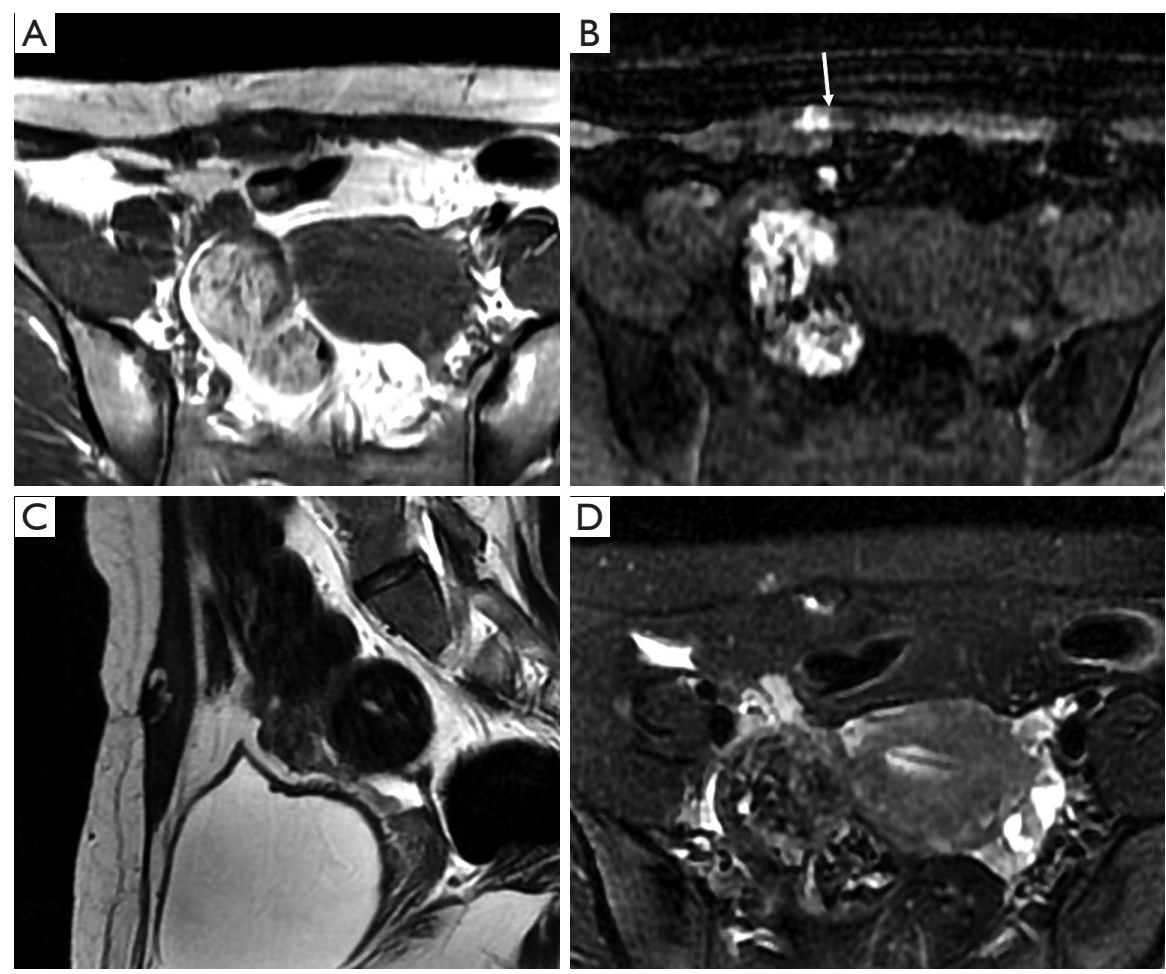

Figure 13 Anterior abdominal wall endometriosis in a 28-year-old woman with a history of cesarean section who presented with persistent cyclical pain symptoms. (A) Axial $T_{1} W I$, (B) $T_{1} W I$ with fat suppression, (C) sagittal $T_{2} W I$ and (D) axial $T_{2} W I$ with fat suppression revealing an irregular, heterogeneous, nodular lesion in the region of the surgical scar. Focal areas of hyperintensity on both $\mathrm{T}_{1} W I$ and $\mathrm{T}_{1} \mathrm{WI}$ with fat suppression (arrow) are present, representing hemorrhage foci. $\mathrm{T}_{1} \mathrm{WI}, \mathrm{T}_{1}$-weighted imaging; $\mathrm{T}_{2} \mathrm{WI}, \mathrm{T}_{2}$-weighted imaging.
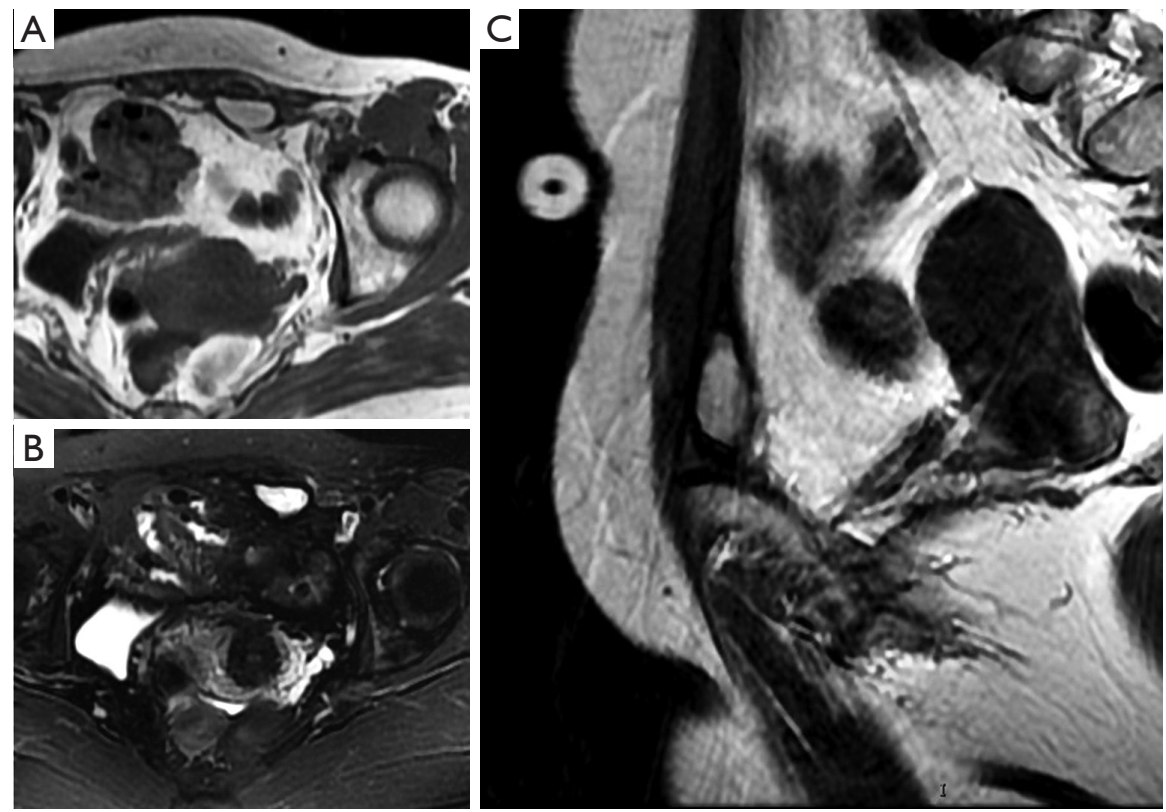

Figure 14 An intramuscular hematoma in the left front abdominal wall of a 40-year-old man. (A) Axial $T_{1} W I$, (B) $T_{2} W I$ with fat suppression, and (C) sagittal $T_{2} W I$ revealing high signals, indicating the presence of methemoglobin. $T_{1} W I, T_{1}$-weighted imaging; $T_{2} W I$, $T_{2}$-weighted imaging. 

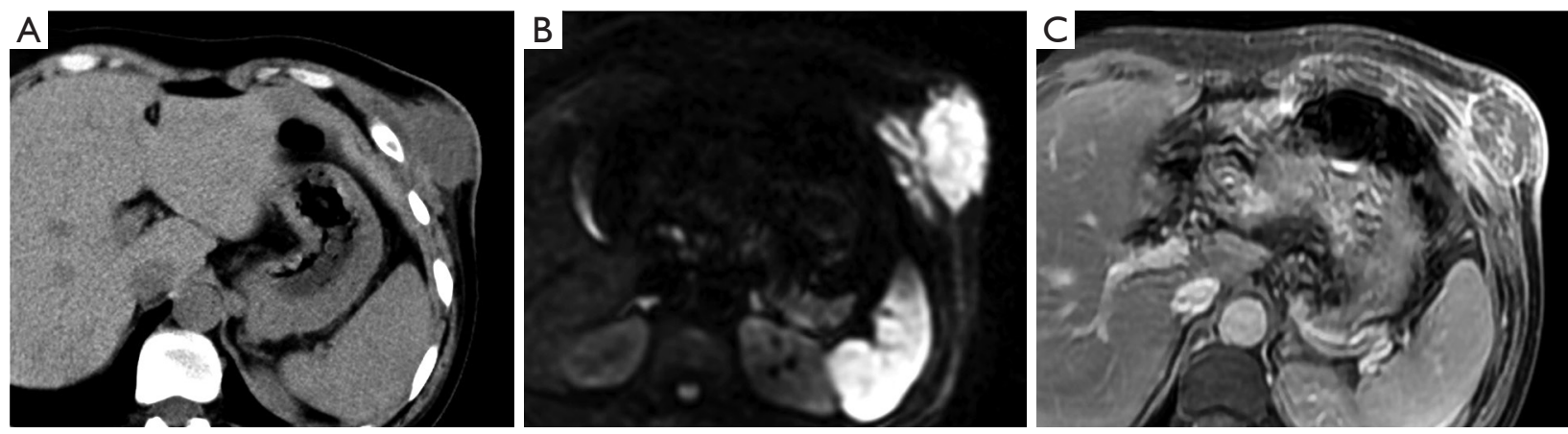

Figure 15 An abscess in the left lateral abdominal wall of a 44-year-old woman. (A) Axial CT showing a low-density, subcutaneous mass in the left lateral abdominal wall; (B) on DWI, the abscess has a very hyperintense signal, which represents restricted diffusion of water molecules in the suppuration; (C) axial contrast-enhanced $\mathrm{T}_{1} \mathrm{WI}$ showing a peripheral rim of enhancement and diffuse inflammation surrounding the nodule after intravenous administration of a contrast agent. $T_{1} W I, T_{1}$-weighted imaging; DWI, diffusion-weighted imaging.

can manifest as a palpable mass (6). Anterior abdominal wall abscesses usually occur postoperatively or secondary to an infected hematoma. Rarely, primary fungal or tubercular abscesses may appear in the muscles or soft tissues of the anterior abdominal wall (3). An abscess is usually indicated by the patient's clinical history and inflammatory skin changes, like erythema and warmth.

The imaging appearance of a soft tissue abscess varies during the process of abscess formation. A mature abscess can contain sufficient internal suppuration, which shows lower fluid density similar to that of fluid on CT. On MRI, the SI varies depending on the amounts of internal proteinaceous debris and necrosis. The increased concentration of protein in the suppuration can result in a high $\mathrm{T}_{1} \mathrm{WI}$ signal. On DWI, abscesses have very hyperintense signals, indicating restricted diffusion of water molecules in the suppuration (Figure 15). The wall of an abscess shows a thick peripheral rim of enhancement after intravenous administration of a contrast agent. Abscesses should be differentiated from myxomatous tumors, such as intramuscular myxomas and myxoid sarcomas, because their high water content and myxoid material both appear hyperintense on $\mathrm{T}_{2} \mathrm{WI}$, mimicking cyst-like lesions. However, myxomatous tumors usually demonstrate internal enhancement. In addition, abscesses may be associated with surrounding diffuse inflammation (65).

\section{Key points and stepwise diagnostic approach}

We summarize the clinical and imaging characterizations of these abdominal wall masses into diagnostic key points in Table 3. In this article, we also propose a practical, systematic stepwise diagnostic approach combining clinical history and imaging appearances, with additional reference to the prevalence of these masses (Table 4). The approach is intended to evaluate abdominal wall masses encountered in daily clinical practice and to highlight some key questions to ask. It should be noted that this stepwise diagnostic approach is based on clinical experience, and the accuracy may be verified in further research. In addition, some abdominal wall masses still remain indeterminate due to the heterogeneous disease spectrum and the lack of characterization. Imaging sometimes even provides a limited capacity to reliably distinguish between benign and malignant lesions. Therefore, a biopsy should be strongly considered for indeterminate masses.

\section{Conclusions}

In summary, an abdominal mass is a common clinical presentation. Although abdominal wall tumors and tumorlike lesions have multiple possible diagnoses, in most cases, an accurate diagnosis can be achieved, or the scope of 
Table 4 Stepwise evaluation of common tumor and tumor-like lesions in the abdominal wall

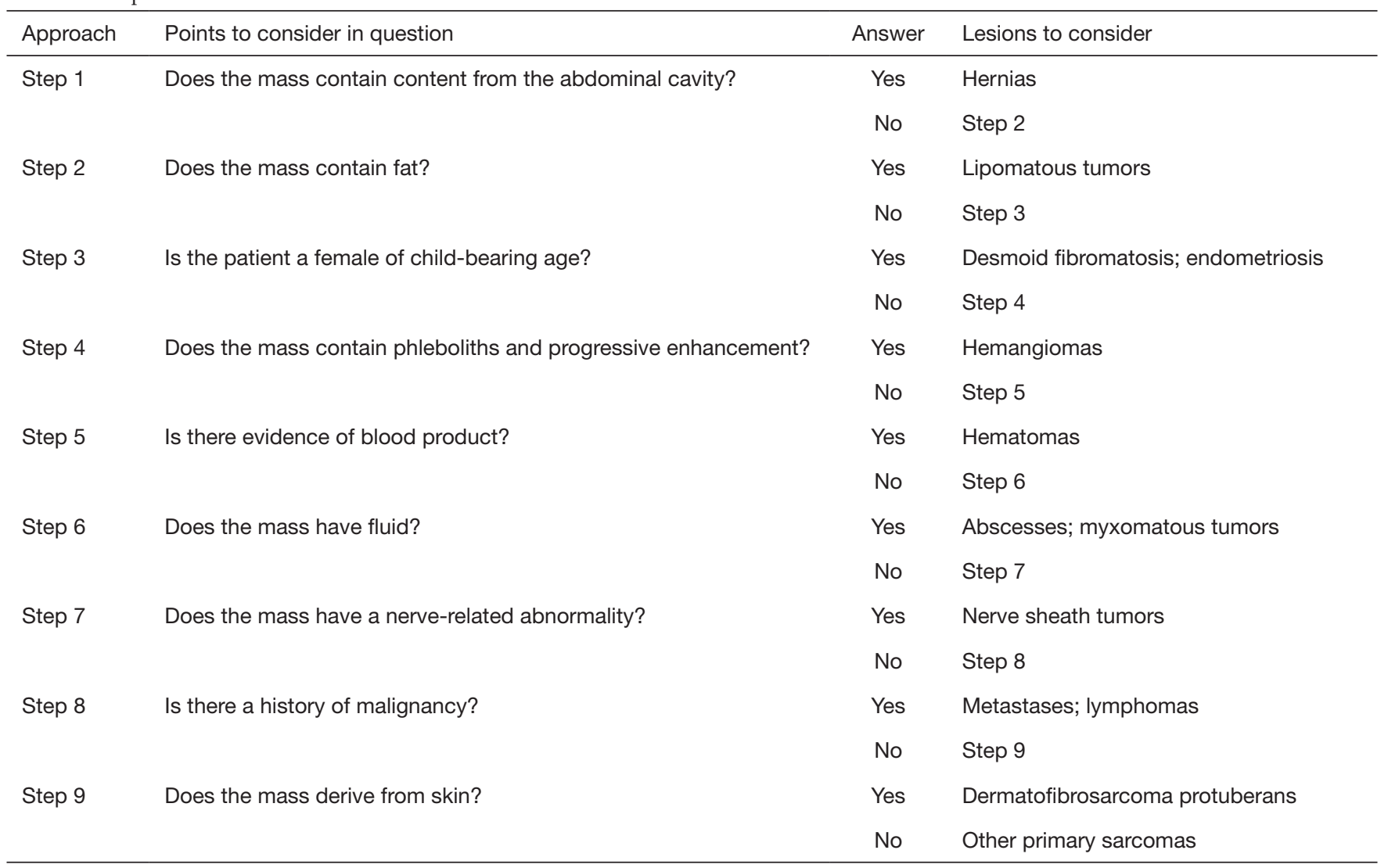

the differential diagnosis can be narrowed by combined assessment of clinical and imaging features. However, a few types of masses still require diagnosis by pathology.

\section{Acknowledgments}

Funding: This study was supported by the Quality Improvement Project for Standardized Residency Training (2018029).

\section{Footnote}

Conflicts of Interest: The authors have no conflicts of interest to declare.

\section{References}

1. Bashir U, Moskovic E, Strauss D, Hayes A, Thway K, Pope R, Messiou C. Soft-tissue masses in the abdominal wall. Clin Radiol 2014;69:e422-31.

2. De Schepper AM, De Beuckeleer L, Vandevenne J,
Somville J. Magnetic resonance imaging of soft tissue tumors. Eur Radiol 2000;10:213-23.

3. Virmani V, Sethi V, Fasih N, Ryan J, Kielar A. The abdominal wall lumps and bumps: cross-sectional imaging spectrum. Can Assoc Radiol J 2014;65:9-18.

4. Jo VY, Fletcher CD. WHO classification of soft tissue tumours: an update based on the 2013 (4th) edition. Pathology 2014;46:95-104.

5. Brennan MF, Antonescu CR, Moraco N, Singer S. Lessons learned from the study of 10,000 patients with soft tissue sarcoma. Ann Surg 2014;260:416-21; discussion 421-2.

6. Beaman FD, Kransdorf MJ, Andrews TR, Murphey MD, Arcara LK, Keeling JH. Superficial soft-tissue masses: analysis, diagnosis, and differential considerations. Radiographics 2007;27:509-23.

7. Myhre-Jensen O. A consecutive 7-year series of 1331 benign soft tissue tumours. Clinicopathologic data. Comparison with sarcomas. Acta Orthop Scand 1981;52:287-93.

8. Murphey MD, Carroll JF, Flemming DJ, Pope TL, Gannon FH, Kransdorf MJ. From the archives of the 
AFIP: benign musculoskeletal lipomatous lesions. Radiographics 2004;24:1433-66.

9. Gupta P, Potti TA, Wuertzer SD, Lenchik L, Pacholke DA. Spectrum of Fat-containing Soft-Tissue Masses at MR Imaging: The Common, the Uncommon, the Characteristic, and the Sometimes Confusing. Radiographics 2016;36:753-66.

10. Williams KJ, Hayes AJ. A guide to oncological management of soft tissue tumours of the abdominal wall. Hernia 2014;18:91-7.

11. Coran A, Ortolan P, Attar S, Alberioli E, Perissinotto E, Tosi AL, Montesco MC, Rossi CR, Tropea S, Rastrelli M, Stramare R. Magnetic resonance imaging assessment of lipomatous soft-tissue tumors. In Vivo 2017;31:387-95.

12. Gaskin CM, Helms CA. Lipomas, lipoma variants, and well-differentiated liposarcomas (atypical lipomas): results of MRI evaluations of 126 consecutive fatty masses. AJR Am J Roentgenol 2004;182:733-9.

13. Murphey MD, Arcara LK, Fanburg-Smith J. From the archives of the AFIP: imaging of musculoskeletal liposarcoma with radiologic-pathologic correlation. Radiographics 2005;25:1371-95.

14. Arkun R, Memis A, Akalin T, Ustun EE, Sabah D, Kandiloglu G. Liposarcoma of soft tissue: MRI findings with pathologic correlation. Skeletal Radiol 1997;26:167-72.

15. Bush CH, Spanier SS, Gillespy T, 3rd. Imaging of atypical lipomas of the extremities: report of three cases. Skeletal Radiol 1988;17:472-5.

16. Jelinek JS, Kransdorf MJ, Shmookler BM, Aboulafia AJ, Malawer MM. Liposarcoma of the extremities: MR and CT findings in the histologic subtypes. Radiology 1993;186:455-9.

17. Kransdorf MJ, Moser RP, Meis JM, Meyer CA. Fatcontaining soft-tissue masses of the extremities. Radiographics 1991;11:81-106.

18. Munk PL, Lee MJ, Janzen DL, Connell DG, Logan PM, Poon PY, Bainbridge TC. Lipoma and liposarcoma: evaluation using CT and MR imaging. AJR Am J Roentgenol 1997;169:589-94.

19. Hosono M, Kobayashi H, Fujimoto R, Kotoura Y, Tsuboyama T, Matsusue Y, Nakamura T, Itoh T, Konishi J. Septum-like structures in lipoma and liposarcoma: MR imaging and pathologic correlation. Skeletal Radiol 1997;26:150-4.

20. Kransdorf MJ, Bancroft LW, Peterson JJ, Murphey MD, Foster WC, Temple HT. Imaging of fatty tumors: distinction of lipoma and well-differentiated liposarcoma.
Radiology 2002;224:99-104.

21. Elbardouni A, Kharmaz M, Berrada MS, Mahfoud M, Elyaacoubi M. Well-circumscribed deep-seated lipomas of the upper extremity. A report of 13 cases. Orthop Traumatol Surg Res 2011;97:152-8.

22. Galant J, Marti-Bonmati L, Saez F, Soler R, AlcalaSantaella R, Navarro M. The value of fat-suppressed T2 or STIR sequences in distinguishing lipoma from welldifferentiated liposarcoma. Eur Radiol 2003;13:337-43.

23. Nassif NA, Tseng W, Borges C, Chen P, Eisenberg B. Recent advances in the management of liposarcoma. F1000Res 2016;5:2907.

24. Murphey MD, Ruble CM, Tyszko SM, Zbojniewicz AM, Potter BK, Miettinen M. From the archives of the AFIP: musculoskeletal fibromatoses: radiologic-pathologic correlation. Radiographics 2009;29:2143-73.

25. Teo HE, Peh WC, Shek TW. Case 84: desmoid tumor of the abdominal wall. Radiology 2005;236:81-4.

26. Lee JC, Thomas JM, Phillips S, Fisher C, Moskovic E. Aggressive fibromatosis: MRI features with pathologic correlation. AJR Am J Roentgenol 2006;186:247-54.

27. Quinn SF, Erickson SJ, Dee PM, Walling A, Hackbarth DA, Knudson GJ, Moseley HS. MR imaging in fibromatosis: results in 26 patients with pathologic correlation. AJR Am J Roentgenol 1991;156:539-42.

28. Robbin MR, Murphey MD, Temple HT, Kransdorf MJ, Choi JJ. Imaging of musculoskeletal fibromatosis. Radiographics 2001;21:585-600.

29. Yacoe ME, Bergman AG, Ladd AL, Hellman BH. Dupuytren's contracture: MR imaging findings and correlation between MR signal intensity and cellularity of lesions. AJR Am J Roentgenol 1993;160:813-7.

30. Torreggiani WC, Al-Ismail K, Munk PL, Nicolaou S, O'Connell JX, Knowling MA. Dermatofibrosarcoma protuberans: MR imaging features. AJR Am J Roentgenol 2002;178:989-93.

31. Kransdorf MJ, Meis-Kindblom JM. Dermatofibrosarcoma protuberans: radiologic appearance. AJR Am J Roentgenol 1994;163:391-4.

32. Daly BD, Currie AR, Choi PC. Case report: computed tomographic and scintigraphic appearances of dermatofibrosarcoma protuberans. Clin Radiol 1993;48:63-5.

33. Zhang L, Liu QY, Cao Y, Zhong JS, Zhang WD. Dermatofibrosarcoma Protuberans: Computed Tomography and Magnetic Resonance Imaging Findings. Medicine (Baltimore) 2015;94:e1001.

34. Zhang J, Li Y, Zhao Y, et al. CT and MRI of superficial 
solid tumors. Quant Imaging Med Surg 2018;8:232-51.

35. Abernethy LJ. Classification and imaging of vascular malformations in children. Eur Radiol 2003;13:2483-97.

36. Vilanova JC, Barcelo J, Smirniotopoulos JG, PerezAndres R, Villalon M, Miro J, Martin F, Capellades J, Ros PR. Hemangioma from head to toe: MR imaging with pathologic correlation. Radiographics 2004;24:367-85.

37. Papp DF, Khanna AJ, McCarthy EF, Carrino JA, Farber AJ, Frassica FJ. Magnetic resonance imaging of soft-tissue tumors: determinate and indeterminate lesions. J Bone Joint Surg Am 2007;89 Suppl 3:103-15.

38. Murphey MD. World Health Organization classification of bone and soft tissue tumors: modifications and implications for radiologists. Semin Musculoskelet Radiol 2007;11:201-14.

39. Murphey MD, Smith WS, Smith SE, Kransdorf MJ, Temple HT. From the archives of the AFIP. Imaging of musculoskeletal neurogenic tumors: radiologic-pathologic correlation. Radiographics 1999;19:1253-80.

40. Vilanova JC, Woertler K, Narvaez JA, Barcelo J, Martinez SJ, Villalon M, Miro J. Soft-tissue tumors update: MR imaging features according to the WHO classification. Eur Radiol 2007;17:125-38.

41. Kurtkaya-Yapicier O, Scheithauer B, Woodruff JM. The pathobiologic spectrum of Schwannomas. Histol Histopathol 2003;18:925-34.

42. Rodriguez FJ, Folpe AL, Giannini C, Perry A. Pathology of peripheral nerve sheath tumors: diagnostic overview and update on selected diagnostic problems. Acta Neuropathol 2012;123:295-319.

43. Xu SY, Sun K, Xie HY, Zhou L, Zheng SS, Wang WL. Hemorrhagic, calcified, and ossified benign retroperitoneal schwannoma: First case report. Medicine (Baltimore) 2016;95:e4318.

44. Banks KP. The target sign: extremity. Radiology 2005;234:899-900.

45. Wu JS, Hochman MG. Soft-tissue tumors and tumorlike lesions: a systematic imaging approach. Radiology 2009;253:297-316.

46. Luzar B, Falconieri G. Cutaneous Malignant Peripheral Nerve Sheath Tumor. Surg Pathol Clin 2017;10:337-43.

47. James AW, Shurell E, Singh A, Dry SM, Eilber FC. Malignant Peripheral Nerve Sheath Tumor. Surg Oncol Clin N Am 2016;25:789-802.

48. Suresh K, Kliot T, Piunti A, Kliot M. Epigenetic mechanisms drive the progression of neurofibromas to malignant peripheral nerve sheath tumors. Surg Neurol Int 2016;7:S797-S800.
49. Goette DK, Deffer TA. Postirradiation malignant fibrous histiocytoma. Arch Dermatol 1985;121:535-8.

50. Levy AD, Manning MA, Miettinen MM. Soft-Tissue Sarcomas of the Abdomen and Pelvis: RadiologicPathologic Features, Part 2-Uncommon Sarcomas. Radiographics 2017;37:797-812.

51. Galant J, Marti-Bonmati L, Soler R, Saez F, Lafuente J, Bonmati C, Gonzalez I. Grading of subcutaneous soft tissue tumors by means of their relationship with the superficial fascia on MR imaging. Skeletal Radiol 1998;27:657-63.

52. Segovis CM, Dyer RB. The "Sister Mary Joseph Nodule". Abdom Radiol (NY) 2017;42:1610-1.

53. Hill M, O'Leary JP. Vignettes in medical history. Sister Mary Joseph and her node. Am Surg 1996;62:328-9.

54. Albano EA, Kanter J. Images in clinical medicine. Sister Mary Joseph's nodule. N Engl J Med 2005;352:1913.

55. Miller T, Ashworth J, Richards S. Sister Mary Joseph nodule. BMJ 2015;351:h5224.

56. Coll DM, Meyer JM, Mader M, Smith RC. Imaging appearances of Sister Mary Joseph nodule. Br J Radiol 1999;72:1230-3.

57. Humphries PD, Sebire NJ, Siegel MJ, Olsen OE. Tumors in pediatric patients at diffusion-weighted MR imaging: apparent diffusion coefficient and tumor cellularity. Radiology 2007;245:848-54.

58. Kim SY, Park JS, Ryu KN, Jin W, Park SY. Various tumormimicking lesions in the musculoskeletal system: causes and diagnostic approach. Korean J Radiol 2011;12:220-31.

59. Aguirre DA, Santosa AC, Casola G, Sirlin CB. Abdominal wall hernias: imaging features, complications, and diagnostic pitfalls at multi-detector row CT. Radiographics 2005;25:1501-20.

60. Gidwaney R, Badler RL, Yam BL, Hines JJ, Alexeeva V, Donovan V, Katz DS. Endometriosis of abdominal and pelvic wall scars: multimodality imaging findings, pathologic correlation, and radiologic mimics. Radiographics 2012;32:2031-43.

61. Granese R, Cucinella G, Barresi V, Navarra G, Candiani M, Triolo O. Isolated endometriosis on the rectus abdominis muscle in women without a history of abdominal surgery: a rare and intriguing finding. J Minim Invasive Gynecol 2009;16:798-801.

62. Busard MP, Mijatovic V, van Kuijk C, Hompes PG, van Waesberghe JH. Appearance of abdominal wall endometriosis on MR imaging. Eur Radiol 2010;20:1267-76.

63. Wolf Y, Haddad R, Werbin N, Skornick Y, Kaplan O. 
Endometriosis in abdominal scars: a diagnostic pitfall. Am Surg 1996;62:1042-4.

64. Täeb S, Penel N, Vanseymortier L, Ceugnart L. Soft tissue sarcomas or intramuscular haematomas? Eur J

Cite this article as: $\mathrm{Li} \mathrm{M}$, Zhang $\mathrm{L}, \mathrm{Xu} \mathrm{XJ}$, Shi Z, Zhao XM. CT and MRI features of tumors and tumor-like lesions in the abdominal wall. Quant Imaging Med Surg 2019;9(11):1820-1839. doi: 10.21037/qims.2019.09.03
Radiol 2009;72:44-9.

65. Hopkins KL, Li KC, Bergman G. Gadolinium-DTPAenhanced magnetic resonance imaging of musculoskeletal infectious processes. Skeletal Radiol 1995;24:325-30. 